\title{
Cage-like Fe,Na-Germsesquioxanes: Structure, Magnetism, and Catalytic Activity
}

\author{
Alexey N. Bilyachenko,* Mikhail M. Levitsky, Alexey I. Yalymov, Alexander A. Korlyukov, \\ Viktor N. Khrustalev, Anna V. Vologzhanina, Lidia S. Shul'pina, Nikolay S. Ikonnikov, \\ Alexander E. Trigub, Pavel V. Dorovatovskii, Xavier Bantreil, Frédéric Lamaty, * Jérôme Long, \\ Joulia Larionova, Igor E. Golub, Elena S. Shubina, and Georgiy B. Shul'pin*
}

\begin{abstract}
A series of four unprecedented heterometallic metallagermsesquioxanes were synthesized. Their cage-like architectures have a unique type of molecular topology consisting of the hexairon oxo $\left\{\mathrm{Fe}_{6} \mathrm{O}_{19}\right\}$ core surrounded in a triangular manner by three cyclic germoxanolates [PhGe(O)O $]_{5}$. This structural organization induces antiferromagnetic interactions between the Fe ${ }^{I I I}$ ions through the oxygen atoms. Evaluated for this first time in catalysis, these compounds showed a high catalytic activity in the oxidation of alkanes and the oxidative formation of benzamides from alcohols.
\end{abstract}

$T_{\text {he design of metal-based polycyclic cage-like compounds }}$ has attracted a great deal of attention from researchers worldwide over several decades owing to their structural diversity and their potential technological applications especially in catalysis. ${ }^{[1]}$ Numerous metal-oxygen clusters, ${ }^{[1, c, j]}$ metal-organic frameworks ${ }^{[1 \mathrm{~d}, 1, \mathrm{~m}]}$ or metal-organic polyhedrons $^{[1 f, n]}$ have been designed by using a variety of selfassembling or templated reactions. Among those, a wide family of polynuclear cage-like metallasilsesquioxanes (CLMSs) architectures with interesting structural topologies $^{[2]}$ and important catalytic activity (e.g. in epoxidation, oxidation and polymerization $)^{[3]}$ has been synthesized through a reaction involving transition-metal ions and silsesquioxane $\left[\mathrm{RSiO}_{1.5}\right]_{n}$ ligands. Surprisingly, examples of cage-like architectures involving another metalloid close to silicon, namely germanium, are scarce despite the great potential of this element in organometallic chemistry. To our knowledge there is only a series of compounds obtained from germasesquioxane $\left[\mathrm{RGeO}_{1.5}\right]_{2}\left(\mathrm{R}=\mathrm{HOOCCH}_{2} \mathrm{CH}_{2}\right)$ and various cations. ${ }^{[4]}$ Their hydrothermal synthesis requires relatively hard conditions consisting of several days of reactions at $110^{\circ} \mathrm{C}$. It is worth mentioning that to date focus has only been on the synthesis, thermogravimetric analysis, luminescence, and sorption properties of these architectures and no investigation of the catalytic activity of metallagermanates has been reported.

Herein, we report an alternative and simplified synthetic approach to design a series of unprecedented individual cagelike metallagermsesquioxanes under mild conditions. In addition, the catalytic activity and magnetic properties of the metallagermsesquioxanes will be discussed.

The single crystals of $\mathrm{Fe}, \mathrm{Na}$-phenylgermsesquioxane $\left[\left(\mathrm{Ph}_{5} \mathrm{Ge}_{5} \mathrm{O}_{10}\right)_{3} \mathrm{Fe}_{6}(\mathrm{OH})_{3}(\mathrm{O}) \mathrm{Na}_{2}\right] \cdot(\mathrm{EtOH})_{2} \cdot \mathrm{H}_{2} \mathrm{O} \mathbf{1}$ (10\% yield) were obtained by a reaction between phenyltrimethoxygermane $\mathrm{PhGe}(\mathrm{OMe})_{3}, \mathrm{NaOH}$ and anhydrous $\mathrm{FeCl}_{3}$ in ethanol with further crystallization. The addition of $\mathrm{N}$-containing ligands, such as phenanthroline, bipyridine, or neocuproine to this reaction allowed us to isolate complexes
[*] Dr. A. N. Bilyachenko, Dr. M. M. Levitsky, A. I. Yalymov,

Prof. A. A. Korlyukov, Prof. V. N. Khrustalev, Dr. A. V. Vologzhanina, L. S. Shul'pina, Dr. N. S. Ikonnikov, Dr. I. E. Golub, Prof. E. S. Shubina A. N. Nesmeyanov Institute of Organoelement Compounds Russian Academy of Sciences

Vavilov str., 28, Moscow (Russia)

E-mail: bilyachenko@ineos.ac.ru

Dr. A. N. Bilyachenko, Prof. V. N. Khrustalev

People's Friendship University of Russia

Miklukho-Maklay Str., 6, 117198, Moscow (Russia)

Prof. A. A. Korlyukov

Pirogov Russian National Research Medical University

Ostrovitianov str., 1, Moscow (Russia)

Dr. A. E. Trigub, P. V. Dorovatovskii

National Research Center "Kurchatov Institute"

Akademika Kurchatova pl., 1, Moscow (Russia)

Dr. J. Long, Prof. J. Larionova

Institut Charles Gerhardt de Montpellier (ICGM), UMR5253, Equipe IMNO, Université de Montpellier

Site Triolet, Place Eugène Bataillon, 34095 Montpellier cedex 5

(France)

\author{
Dr. X. Bantreil, Dr. F. Lamaty \\ Institut des Biomolécules Max Mousseron (IBMM), UMR 5247 \\ CNRS \\ Université Montpellier, ENSCM CNRS, Université de Montpellier, \\ ENSCM should be on the same line \\ Université de Montpellier Campus Triolet, Place Eugène Bataillon, \\ 34095 Montpellier cedex 5 (France) \\ E-mail: frederic.lamaty@umontpellier.fr \\ Prof. G. B. Shul'pin \\ Semenov Institute of Chemical Physics \\ Russian Academy of Sciences \\ Ulitsa Kosygina, dom 4, Moscow 119991 (Russia) \\ E-mail: shulpin@chph.ras.ru \\ Prof. G. B. Shul'pin \\ Plekhanov Russian University of Economics \\ Stremyannyi pereulok, dom 36, Moscow 117997 (Russia)
}


$\left[\left(\mathrm{Ph}_{5} \mathrm{Ge}_{5} \mathrm{O}_{10}\right)_{3} \mathrm{Fe}_{6}(\mathrm{OH})_{3}(\mathrm{O}) \mathrm{Na}_{2}(\right.$ phen $\left.)\right] \cdot \quad(\mathrm{EtOH})_{4} \cdot \quad\left(\mathrm{H}_{2} \mathrm{O}\right)_{0.5}$ (2), $\quad\left[\left(\mathrm{Ph}_{5} \mathrm{Ge}_{5} \mathrm{O}_{10}\right)_{6} \mathrm{Fe}_{6}(\mathrm{OH})_{3} \mathrm{OFe}_{6}(\mathrm{OH})_{2}(\mathrm{O})_{2} \mathrm{Na}_{3}\right.$ (bipy) $]$. $(\mathrm{EtOH})_{14.5} \cdot\left(\mathrm{C}_{5} \mathrm{H}_{5} \mathrm{~N}\right)_{0.5} \cdot\left(\mathrm{H}_{2} \mathrm{O}\right)(\mathbf{3})$, and $\left[\left(\mathrm{Ph}_{5} \mathrm{Ge}_{5} \mathrm{O}_{10}\right)_{3} \mathrm{Fe}_{6}{ }^{-}\right.$ $(\mathrm{OH})_{3}(\mathrm{O}) \mathrm{Na}_{2}$ (neocuproine) $] \cdot \quad(\mathrm{EtOH})_{2} \cdot \quad\left(\mathrm{H}_{2} \mathrm{O}\right)_{1.5} \quad$ (4; Scheme S1 in the Supporting Information) in higher yields (up to $26 \%$ ). Single-crystal X-ray diffraction analyses of 1-4 revealed similar structural organization with the cage-like molecular architecture. The complexes are formed by a central hexairon(III) oxo $\left\{\mathrm{Fe}_{6} \mathrm{O}_{19}\right\}$ core, reminiscent of the "Lindqvist polyanion", coordinated by three pentameric germoxanolate $\left[\mathrm{PhGe}(\mathrm{O}) \mathrm{O}^{-}\right]_{5}$ ligands, forming an unprecedented three-pointed star geometry.

In the representative crystal structure of $\mathbf{1}$, the octahedral iron ions are located in vertexes of an octahedron (Figure 1). They are connected through the central and peripheral oxygen atoms. $\mathrm{Fe}-\mathrm{O}(\mathrm{Fe})$ distances are in the range of 1.99 $2.05 \AA$, those of $\mathrm{Fe}-\mathrm{O}(\mathrm{Ge})$ and $\mathrm{Fe}-\mathrm{Fe}$ are in the range of 1.87-1.90 $\AA$ and 3.16-3.27 $\AA$, respectively. In turn, the values of the $\mathrm{Fe}-\mathrm{O}-\mathrm{Fe}$ angle depend on the position of the oxygen atom. It is close to $90^{\circ}$ when the oxygen occupies the central position and significantly exceeds $90^{\circ}$ in the other cases $\left(\Varangle \mathrm{Fe}-\mathrm{O} 1-\mathrm{Fe}: 88.1-91.7^{\circ} ; \not<\mathrm{Fe}-\mathrm{O}-\mathrm{Fe}: 101.9-108.2^{\circ}\right)$. The
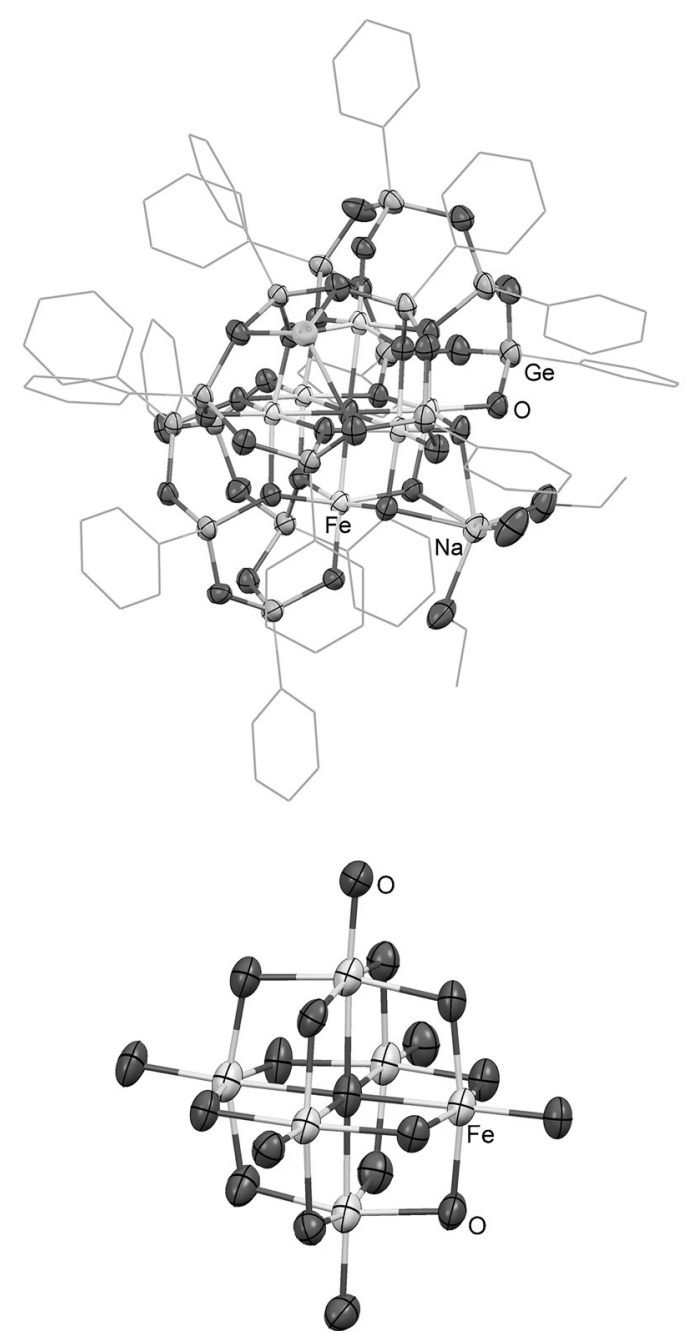

Figure 1. Top: Molecular structure of 1. Bottom: The structure of $\mathrm{Fe}_{6} \mathrm{O}_{19}$ core of 1. Full color version is given in ESI (Figures $\mathrm{S} 1, \mathrm{~S} 2$ ).
Pentameric germoxanolate fragment of $\mathbf{1}$ adopts a crown configuration (Figure S1), with the main structural parameters: $\mathrm{Ge}-\mathrm{O}(\mathrm{Ge}) 1.740-1.791 \AA, \measuredangle \mathrm{Ge}^{-} \mathrm{O}-\mathrm{Ge} 117.6-129.0^{\circ}$. Note that the only example of cyclic germanoxane fragments in metallagermsesquioxane structures describe hexameric units. ${ }^{[4 a]}$ The structural organization of the related compounds 2-4 is similar to $\mathbf{1}$. The difference consists in additional coordination of the respective bidentate ligands (1,10-phenanthroline, 2,2'-bipyridine, neocuproine) to the $\mathrm{Na}$ ions (Figure S2). Noteworthy is that sodium ions are located in external positions to the cage and, thus, are responsible for the supramolecular packing (Figure S3). According to the higher yields of 2-4 in comparison to $\mathbf{1}$, bidentate ligands might give additional stabilization of the metallagermsesquioxane cage and facilitate its crystallization. These results show that germsesquioxanes indeed provide great potential for creation of cage metalladerivatives, even when using simple alkoxygermane as an initial reagent. Drawing an analogy between Fe-based sesquioxanes of germanium and silicon, we would like to emphasize that known types of cage ironsilsesquioxanes (Refs. [2a,c,j]) have quite different structural features in comparison to germanium-based compounds 1-4. This suggests a unique role of germanium centers in cagecompound formation. Results of EXAFS study on iron and germanium K-edges for 1-4 confirmed that the oxidation states of iron and germanium are +3 and +4 , respectively (Figures S4-S5, Tables S3-S4).

The magnetic properties of these compounds, investigated by using a SQUID magnetometer working in the temperature range $1.8-300 \mathrm{~K}$ up to $7 \mathrm{~T}$, indicate that they are paramagnetic behavior in this temperature range. The temperature dependence of the magnetic susceptibility for $\mathbf{1}$ is given as an example (Figure S7, ESI). The room temperature value of $\chi T$, equal to $14.29 \mathrm{~cm}^{3} \mathrm{~K} \mathrm{~mol}^{-1}$, is considerably lower than the theoretical one of $26.25 \mathrm{~cm}^{3} \mathrm{~K} \mathrm{~mol}^{-1}$, expected for six non-interacting $\mathrm{Fe}^{\mathrm{III}}$ ions $(S=5 / 2$ and $g=2.00)$. Such a discrepancy most likely originates from the occurrence of strong antiferromagnetic interactions between the spin carriers that are still operative at room temperature. This is indeed confirmed by the temperature dependence of $\chi T$, which reveals a progressive decrease upon cooling to reach $3.80 \mathrm{~cm}^{3} \mathrm{~K} \mathrm{~mol}^{-1}$ at $1.8 \mathrm{~K}$. Antiferromagnetic interactions between the $\mathrm{Fe}^{\mathrm{III}}$ ions can be mediated through both the central and bridging oxygen atoms, as found in similar hexanuclear architectures. ${ }^{[5]}$ For temperatures lower than $10 \mathrm{~K}$, a steep decrease of $\chi T$ occurs and can be assigned to the zero-field splitting and/or intermolecular interactions between the polynuclear complexes. In addition, the non-null value of $\chi T$ at low temperature indicates the presence of a non-diamagnetic ground state that should be expected for a pure $S=0$ species. This could reflect either the presence of thermally populated excited states or antagonist magnetic interactions mediated by the different bridging oxygen atoms. The field dependence of the magnetization at $1.8 \mathrm{~K}$ for $\mathbf{1}$ further confirms the nondiamagnetic state with a magnetization value of $2.72 \mu_{\mathrm{B}}$ without any evidence of the saturation indicating the presence of a magnetic anisotropy (Figure S8). Alternating current (AC) measurements performed as the temperature dependence of the in-phase $\left(\chi^{\prime}\right)$ and out-of-phase $\left(\chi^{\prime \prime}\right)$ susceptibilities 
measured in a zero DC magnetic field show an increase upon cooling but without the presence of a maximum, precluding an in-depth characterization of the relaxation dynamics (Figure S9).

We also present herein the first applications of cage metallagermsesquioxanes in catalysis. As complexes 1-4 have similar molecular architectures, we concentrated on the study of one of them as an example, namely, compound 2 . It is well established that iron-based compounds ${ }^{[6]}$ are capable of catalyzing the oxidation of hydrocarbons with peroxides. We have found that cyclohexane and other alkanes as well as benzene can be oxidized to the alkyl hydroperoxides and phenol, respectively, by hydrogen peroxide in the presence of catalytic amounts of $\mathbf{2}$ and $\mathrm{CF}_{3} \mathrm{COOH}$ (some examples are shown in Figure 2, the experimental details are described in

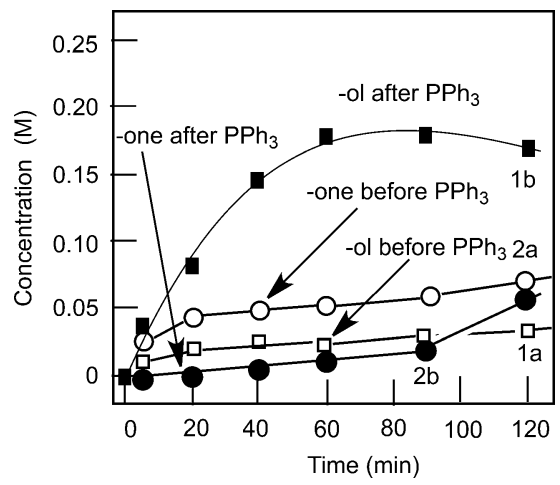

Figure 2. Accumulation of oxygenates (cyclohexanol, curves 1, and cyclohexanone, curves 2$)$ in the oxidation of cyclohexane $(0.46 \mathrm{M})$ with $\mathrm{H}_{2} \mathrm{O}_{2}(50 \%$, aqueous, $1.5 \mathrm{M})$ catalyzed by $2\left(5 \times 10^{-4} \mathrm{M}\right)$ in the presence of $\mathrm{CF}_{3} \mathrm{COOH}(0.05 \mathrm{M})$. Solvent was acetonitrile (total volume of the reaction solution was $5 \mathrm{~mL}$ ) at $40^{\circ} \mathrm{C}$. Concentrations of cyclohexanone and cyclohexanol were determined before (curves a) and after (curves b) reduction of the aliquots with solid $\mathrm{PPh}_{3}$ (for this method, see Ref. [7]).

the Supporting Information). The oxidation with $\mathrm{H}_{2} \mathrm{O}_{2}$ catalyzed by complex $\mathbf{2}$ was very efficient as it gave oxygenates from alkanes in a very high yield of $44 \%$. This yield is one of the highest values obtained so far in metal-catalyzed oxidations of cyclohexane with $\mathrm{H}_{2} \mathrm{O}_{2}$ since usually yields are not higher than 5-30\%. For example, cyclohexane oxidation ${ }^{[6 c]}$ with $\mathrm{H}_{2} \mathrm{O}_{2}$ catalyzed by a hexanuclear iron(III) carboxylate gave maximum yield of oxygenates of $29 \%$.

The S-shape mode of the initial rate $W_{0}$ dependence on the concentration of $\mathbf{2}$ attests that the reaction order with respect to $\mathbf{2}$ is not constant and gradually changes from an apparent second order to first order, when $[\mathbf{2}]_{0}$ changes in the interval from $1.5 \times 10^{-4}$ to $3 \times 10^{-4} \mathrm{M}$ (Figure 3).

On the basis of these data, a mechanism can be proposed which includes a stage of the starting complex monomerization. ${ }^{[2 c]}$ Further dimerization of these particles affords species which are responsible for the catalytic activity of the system.

Dependence of the initial oxidation rate on the concentration of the $\mathrm{CF}_{3} \mathrm{COOH}$ co-catalyst is given in Figure S10. The dependence of $W_{0}$ on the initial concentration of cyclohexane approaches a plateau at $[\mathrm{CyH}]_{0}>0.4 \mathrm{M}$ (Fig-

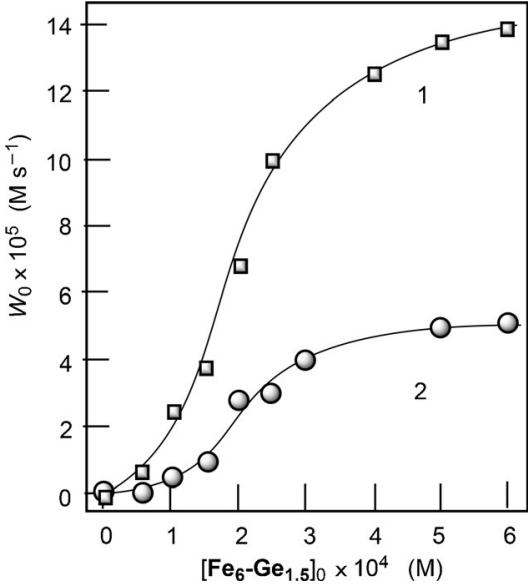

Figure 3. Dependence of the initial rate of oxygenate (the sum cyclohexanol + cyclohexanone) formation $W_{0}$ on the initial concentration of 2 in the oxidation of cyclohexane $(0.46 \mathrm{M}$, curve 1$)$ and benzene ( $0.45 \mathrm{M}$, curve 2 ) with hydrogen peroxide ( $50 \%$ aqueous) in the presence of $\mathrm{CF}_{3} \mathrm{COOH}(0.05 \mathrm{M})$ in $\mathrm{MeCN}$ at $40^{\circ} \mathrm{C}$. Concentrations of cyclohexanone and cyclohexanol were determined after reduction of the aliquots with solid $\mathrm{PPh}_{3}$.

ure S11) indicating a competitive interaction of the oxidizing species with the alkane and acetonitrile. ${ }^{[8]}$ The rate dependence on the initial concentration of hydrogen peroxide is linear at $\left[\mathrm{H}_{2} \mathrm{O}_{2}\right]_{0}<1.5 \mathrm{~m}$ (Figure $\left.\mathrm{S} 12\right)$.

Complex 2 was also evaluated in the formation of amides directly from alcohols and amines, in the presence of tert-butyl hydroperoxide as the terminal oxidant. For this purpose, we chose the newly developed metal-catalyzed microwave-activated amidation $^{[9,2 c]}$ between benzylic alcohol and $( \pm)$ - $\alpha$ methylbenzylammonium chloride (Scheme 1). The use of

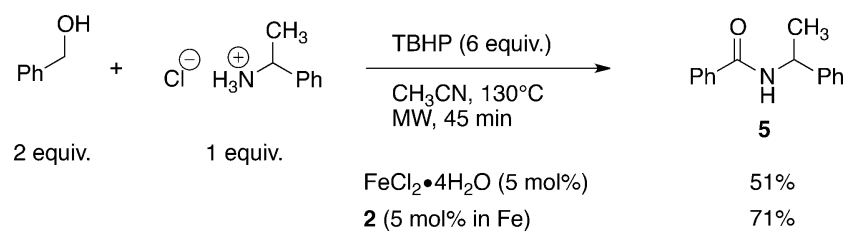

Scheme 1. Microwave activation by 2 or $\mathrm{FeCl}_{2} \cdot 4 \mathrm{H}_{2} \mathrm{O}$.

complex 2 allowed amide 5 to be obtained in a yield of $71 \%$. This result was compared to that obtained with a more simple iron salt, $\mathrm{FeCl}_{2} \cdot 4 \mathrm{H}_{2} \mathrm{O}$, which gave the product in a yield of only $51 \%$. This result clearly shows that the germsesquioxane structure exerts a stabilizing effect around the metallic center, resulting in an improved catalytic activity.

In conclusion, a family of unprecedented cage-like $\mathrm{Fe}, \mathrm{Na}-$ germsesquioxanes having a central hexairon(III) oxo $\left\{\mathrm{Fe}_{6} \mathrm{O}_{19}\right\}$ core coordinated by three pentameric germoxanolate ligands has been obtained. Their structural arrangement induces antiferromagnetic interactions between $\mathrm{Fe}^{\mathrm{III}}$ ions through the oxygen bridges resulting in a paramagnetic behavior. This class of compounds was evaluated for the first time for its catalytic activity. Complex 2, displayed a high efficiency in catalysis for alkane oxidation and amide formation from benzylic alcohol and amine. A further investigation on the 
design of new metallagermsesquioxanes with different structural organization and catalytic properties is currently in progress. These results, concerning an influence of composition and structure of such cage complexes on catalytic behavior (including possible synergetic effect of metal and germanium ions as catalytic centers) will be presented in the near future.

\section{Acknowledgements}

This work was supported by RFBR (projects 16-03-00609, 1603-00206, 16-03-00254, 16-29-05180, 16-53-150008). French Embassy in Moscow, Balard Foundation, University of Montpellier, CNRS (Programme de Recherche Conjoint), and the Plateforme D'Analyse et de Caractérisation (PAC Balard), and "Science without Borders Program, BrazilRussia”, CAPES (grant A017-2013).

Keywords: cage compounds · homogeneous catalysis . metallagermsesquioxanes - oxidation - structure elucidation

[1] a) M. Veith, Chem. Rev. 1990, 90,3-16; b) M. T. Pope, A. Muller, Angew. Chem. Int. Ed. Engl. 1991, 30, 34-48; Angew. Chem. 1991, 103, 56-70; c) Special issue on polyoxometalates (Ed.: C. L. Hill), Chem. Rev. 1998, 98, 1; d) O. M. Yaghi, M. O'Keeffe, N. W. Ockwig, H. K. Chae, M. Eddaoudi, J. Kim, Nature 2003, 423, 705 714 ; e) R. Murugavel, A. Choudhury, M. G. Walawalkar, R. Pothiraja, C. N. R. Rao, Chem. Rev. 2008, 108, 3549-3655; f) D. J. Tranchemontagne, Z. Ni, M. O'Keeffe, O. M. Yaghi, Angew. Chem. Int. Ed. 2008, 47, 5136-5147; Angew. Chem. 2008, 120, 5214-5225; g) T. S. Koblenz, J. Wassenaar, J. N. H. Reek, Chem. Soc. Rev. 2008, 37, 247-262; h) S. J. Dalgarno, N. P. Power, J. L. Atwood, Coord. Chem. Rev. 2008, 252, 825-841; i) R. Chakrabarty, P. S. Mukherjee, P. J. Stang, Chem. Rev. 2011, 111, 68106918 ; j) H. N. Miras, J. Yan, D.-L. Long, L. Cronin, Chem. Soc. Rev. 2012, 41, 7403-7430; k) M. M. J. Smulders, I. A. Riddell, C. Browne, J. R. Nitschke, Chem. Soc. Rev. 2013, 42, 1728-1754; 1) H. Furukawa, K. E. Cordova, M. O'Keeffe, O. M. Yaghi, Science 2013, 341, 1230444; m) S. Chaemchuen, N. A. Kabir, K. Zhou, F. Verpoort, Chem. Soc. Rev. 2013, 42, 9304-9332; n) N. Ahmad, A. H. Chughtai, H. A. Younus, F. Verpoort, Coord. Chem. Rev. 2014, 280, 1-27.

[2] a) M. M. Levitsky, A. N. Bilyachenko, Coord. Chem. Rev. 2016, 306, 235-269; b) E. V. Beletskiy, Z. Shen, M. V. Riofski, X. Hou, J. R. Gallagher, J. T. Miller, Y. Wu, H. H. Kung, M. C. Kung, Chem. Commun. 2014, 50, 15699; c) A. N. Bilyachenko, M. M. Levitsky, A. I. Yalymov, A. Korlyukov, A. Vologzhanina, Yu. Kozlov, L. Shul'pina, D. Nesterov, A. Pombeiro, F. Lamaty, X. Bantreil, A. Fetre, D. Liu, J. Martinez, J. Long, J. Larionova, Y. Guari, A. Trigub, Y. Zubavichus, I. E. Golub, O. A. Filippov, E. S.
Shubina, G. B. Shul'pin, $R S C A d v$. 2016, 6, 48165-48180; d) A. N. Bilyachenko, A. I. Yalymov, L. S. Shul'pina, D. Mandelli, A. A. Korlyukov, A. V. Vologzhanina, M. A. Es'kova, E. S. Shubina, M. M. Levitsky, G. B. Shul'pin, Molecules 2016, 21, 665; e) E. V. Beletskiy, Y. Wu, M. C. Kung, H. H. Kung, Organometallics 2016, 35, 301-302; f) M. S. Raj Prabhu, U. Ugandhara, V. Baskar, Dalton Trans. 2016, 45, 6963-6967; g) A. N. Bilyachenko, A. I. Yalymov, A. Korlyukov, J. Long, J. Larionova, Y. Guari, A. V. Vologzhanina, M. Eskova, E. S. Shubina, M. M. Levitsky, Dalton Trans. 2016, 45, 7320-7327; h) A. N. Bilyachenko, A. I. Yalymov, M. M. Levitsky, A. Korlyukov, M. Eskova, J. Long, J. Larionova, Y. Guari, L. S. Shul'pina, N. S. Ikonnikov, A. Trigub, Y. V. Zubavichus, I. E. Golub, E. S. Shubina, G. B. Shul'pin, Dalton Trans. 2016, 45, 13663 -13666; i) K. S. Lokare, N. Frank, B. BraunCula, I. Goikoetxea, J. Sauer, C. Limberg, Angew. Chem. Int. Ed. 2016, 55, 12325-12329; Angew. Chem. 2016, 128, 12513-12517; j) A. N. Bilyachenko A. I. Yalymov, M. M. Levitsky, A. A. Korlyukov, V. N. Khrustalev, L. S. Shul'pina, P. V. Dorovatovskii, M. A. Es'kova, F. Lamaty, X. Bantreil, B. Villemejeanne, J. Martinez, Y. N. Kozlov, N. V. Vorontsov, E. S. Shubina, G. B. Shul'pin, unpublished results.

[3] a) E. A. Quadrelli, J.-M. Basset, Coord. Chem. Rev. 2010, 254, 707-728; b) A. J. Ward, A. F. Masters, T. Maschmeyer, $A d v$. Silicon Sci. 2011, 3, 135-166; c) M. M. Levitsky, A. I. Yalymov, A. N. Kulakova, A. A. Petrov, A. N. Bilyachenko, J. Mol. Catal. A 2016, DOI: 10.1016/j.molcata.2016.06.016.

[4] a) H. He, G.-J. Cao, S.-T. Zheng, G.-Y. Yang, J. Am. Chem. Soc. 2009, 131, 15588 -15589; b) G.-J. Cao, S.-T. Zheng, N. Zhao, J.-K. Sun, G.-Y. Yang, Inorg. Chem. 2010, 49, 10211-10213; c) N. Stock, C. Jargstorff, S. Wriedt, Z. Anorg. Allg. Chem. 2011, 637, $572-577$; d) C. Schmidt, A. Lieb, N. Stock, Z. Anorg. Allg. Chem. 2011, 637, 2163-2168; e) C. Schmidt, N. Stock, Cryst. Growth Des. 2011, 11, 5682-5687; f) G.-J. Cao, Q.-L. Li, C. Rong, Chinese J. Struct. Chem. 2013, 32, 1250-1256.

[5] A. Cornia, D. Gatteschi, K. Hegetschweiler, L, Hausherr-Primo, V. Gramlich, Inorg. Chem. 1996, 35, 4414-4419.

[6] a) Iron Catalysis in Organic Chemistry (Ed.: B. Plietker), WileyVCH, Weinheim, 2008; b) K. Schröder, K. Junge, B. Bitterlich, M. Beller, Top. Organomet. Chem. 2011, 33, 83-109; c) G. Trettenhahn, M. Nagl, N. Neuwirth, V. B. Arion, W. Jary, P. Pöchlauer, W. Schmid, Angew. Chem. Int. Ed. 2006, 45, 2794-2798; Angew. Chem. 2006, 118, 2860-2865.

[7] a) G. B. Shul'pin, J. Mol. Catal. A 2002, 189, 39-66; b) G. B. Shul'pin, Catalysts 2016, 6, paper no. 50.

[8] a) D. S. Nesterov, E. N. Chygorin, V. N. Kokozay, V. V. Bon, R. Boča, Y. N. Kozlov, L. S. Shul'pina, J. Jezierska, A. Ozarowski, A. J. L. Pombeiro, G. B. Shul'pin, Inorg. Chem. 2012, 51, $9110-$ 9122; b) G. B. Shul'pin, Y. N. Kozlov, L. S. Shul'pina, W. Carvalho, D. Mandelli, RSC Adv. 2013, 3, 15065-15074; c) M. M. Vinogradov, L. S. Shul'pina, Y. N. Kozlov, A. R. Kudinov, N. S. Ikonnikov, G. B. Shul'pin, J. Organomet. Chem. 2015, 784, 52-61.

[9] X. Bantreil, P. Navals, J. Martinez, F. Lamaty, Eur. J. Org. Chem. 2015, $417-422$. 